\title{
A PROPOSTA PEDAGÓGICA DO TEACHING GAMES FOR UNDERSTANDING: REFLEXÕES SOBRE A INICIAÇÃO ESPORTIVA
}

\section{Sabine Zink Bolonhini}

Universidade Estadual de Campinas, São Paulo, Brasil.

\author{
Roberto Rodrigues Paes
}

Universidade Estadual de Campinas, São Paulo, Brasil.

\begin{abstract}
Resumo
A proposta do Teaching Games for Understanding (TGFU) defende que a iniciação esportiva se baseie em jogos reduzidos. Para autores que seguem essa linha teórica, a prática destes jogos contribui para a compreensão da lógica tática do jogo formal. Este artigo tem como principal objetivo realizar discussões sobre a proposta do TGFU. Essa proposta ocupa um papel importante nas publicações mundiais sobre ensino e aprendizagem esportiva. Com isso, procuramos relacionar as propostas de autores do TGFU às reflexões de estudiosos da Pedagogia do Esporte no Brasil. A partir do diálogo entre esses dois grupos de autores, o dos autores que discutem o TGFU e os autores brasileiros que estudam a Pedagogia do Esporte, é possível contribuir para a construção de novos olhares sobre o fenômeno da iniciação esportiva.

Palavras-chave: Esporte - Pedagogia - Iniciação esportiva - Teaching Games For Understanding.
\end{abstract}

\section{Introdução}

$\mathrm{O}$

Esporte Contemporâneo corresponde a um fenômeno histórico, social e cultural, que envolve diferentes dimensões e, com isso, diversas possibilidades de análise e discussões. Ou seja, é um fenômeno plural que pode ser estudado a partir de diferentes perspectivas, seja histórica, econômica, política, fisiológica, psicológica, entre diversas outras. Neste estudo, voltaremos o olhar para o aspecto que envolve a Pedagogia do Esporte, desse modo, procuraremos aprofundar as discussões sobre o ensino e aprendizagem do esporte e a complexidade envolvida no processo de vivência esportiva.

As produções teóricas sobre a Pedagogia do Esporte e Iniciação Esportiva são variadas, apresentando diferentes possibilidades de eixos teóricos e abordagens. No Brasil, os estudos sobre esses temas tiveram forte influência de autores portugueses que discutiram propostas pedagógicas dentro dos Jogos Desportivos Coletivos. As publicações de autores como Bento, Garganta, Graça, entre outros, foram referência de muitos autores brasileiros que estudaram a Pedagogia do Esporte e o processo de iniciação esportiva. É importante ressaltar as contribuições que esse grupo de autores teve para o avanço no campo teórico da Pedagogia do Esporte no Brasil.

Com o objetivo de contribuir para ampliação e diversificação das discussões acerca da Pedagogia do Esporte, este estudo tem suporte teórico em autores que abordam esse tema a partir da proposta de ensino chamada de Teaching Games for Understan- 
ding (TGFU), relacionando suas propostas às reflexões de outros estudiosos da iniciação esportiva. A teoria do TGFU é apresentada inicialmente por Bunker e Thorpe (1986), na Inglaterra. A partir desta primeira publicação, a proposta pedagógica ganhou força, e outros pesquisadores publicam artigos contribuindo para a ampliação e aprofundamento das reflexões sobre o TGFU.

O TGFU propõe uma forma de ensino contextualizada, isto é, sugere que as aulas de iniciação esportiva se baseiem em jogos reduzidos. Estes jogos podem ter espaço reduzido, menos jogadores, equipamentos adaptados, tempo de jogo reduzido, enfim, possuem regras adaptadas em relação ao jogo formal. No entanto, é importante que a estrutura tática destes jogos reduzidos seja semelhante a do jogo formal. Dessa forma, o aluno compreende a lógica do jogo, sendo capaz de responder de maneira inteligente às situações que aparecem durante o jogo. Portanto, segundo a abordagem do TGFU, o foco está em fazer com que o aluno compreenda a tática antes de preocupar-se com a aprendizagem dos gestos técnicos.

\section{A proposta pedagógica do teaching games for understanding}

Bunker e Thorpe (1986) introduziram a discussão da proposta de ensino pautada no TGFU. Os autores realizam uma discussão teórica que estabelece as diretrizes e fundamenta teoricamente o modelo proposto, além de estabelecer um guia para o planejamento de aulas pautadas nessa linha.

O principal ponto criticado por Bunker e Thorpe (1986) é a linha pedagógica na qual as aulas de iniciação esportiva estavam tradicionalmente pautadas. Ou seja, aulas que se estruturavam a partir de atividades analíticas, desvinculadas do contexto do jogo e que visavam o ensino de habilidades técnicas. $\mathrm{O}$ pressuposto teórico que orienta o modelo tecnicista é o de que, uma vez aprendidos os gestos técnicos, o aluno está apto para jogar o jogo formal. Em outras palavras, o jogo é dividido em elementos técnicos que são ensinados isoladamente. A partir disso, a expectativa é a de que o aluno saiba aplicar esses elementos no jogo de maneira eficiente.

Segundo Light (2007), aulas de iniciação esportiva que se baseiam no ensino de habilidades técnicas, estruturadas a partir da repetição de gestos, geram pouco interesse nos alunos. Para o autor, esse modelo tradicional de ensino reduz as possibilidades educacionais e a complexidade do contexto que a iniciação esportiva envolve. Aprender a jogar qualquer jogo envolve aspectos como a percepção, a resolução de problemas, tomadas de decisão e resposta às informações do ambiente.

Esse aspecto da percepção e resolução de problemas também é discutido por Balbino e Paes (2005). Segundo os autores, é importante que o processo de iniciação esportiva seja marcado pela variedade das atividades realizadas durante as aulas. Os professores devem promover diferentes jogos para que a criança entre em contato com uma diversificação de movimentos e pluralidade de situações-problema. Dessa forma, contribui-se de maneira significativa para a aquisição de habilidades motoras e para a percepção de variadas situações-problema e a busca por respostas inteligentes e criativas para elas.

Mitchell, Oslin e Griffin (2003) também discutem o contexto do jogo a partir da perspectiva do TGFU. Para eles, as crianças aprendem a solucionar os pro- 
blemas táticos durante a vivência do jogo. É importante que o professor realize uma análise das ações dos alunos durante os jogos e, após identificar os problemas táticos, elabore uma sequência de atividades que possam solucionar estes problemas. Este processo se dá a partir da realização de atividades mais simples em direção a atividades com situações-problema mais complexas. A partir destas reflexões, corroboramos com a proposta de Sadi, Costa e Sacco (2008) que aproxima a proposta do TGFU ao contexto da Educação Física escolar. De acordo com esses autores, é importante que o processo de planejamento de aulas de Educação Física esteja fundamentado em elementos teóricos do TGFU. É de fundamental importância que os jogos propostos em aula estejam adequados ao nível dos alunos. Com o decorrer das aulas, deve haver um aumento no nível de complexidade das atividades de forma a promover um desenvolvimento na percepção tática e compreensão do jogo por parte dos alunos.

A proposta pedagógica TGFU, conforme sugerem Light e Fawns (2003), encara o jogo como um contexto que oferece a possibilidade de aprendizagem a partir da integração de elementos sociais, culturais, físicos e emocionais. Essa perspectiva aponta para a importância e complexidade da idéia central do TGFU, segundo a qual a aprendizagem dos esportes deve ocorrer dentro e a partir do contexto do jogo. Dessa forma, o conhecimento é construído nas relações que o aluno estabelece dentro da situação da aula, isto é, as habilidades e a compreensão do jogo, construídas durante a aula, estão relacionadas ao ambiente físico, social e cultural.

É importante ressaltar que o jogo corresponde a um momento que proporciona situações variadas e imprevisíveis. É composto por uma rede de elementos que se relacionam promovendo experiências significativas que podem contribuir com a formação da criança. Paes (2001) também defende o jogo como uma importante ferramenta pedagógica no processo de iniciação esportiva. Segundo o autor, o jogo oferece a possibilidade de acentuar a ludicidade de uma prática esportiva, envolve aspectos sociais, culturais, psicológicos, cognitivos, emocionais. Ao jogar, a criança aprende a lidar com os companheiros, com os adversários, com situações de adversidade que requerem inteligência e criatividade para serem solucionadas, aprende a importância das regras, a necessidade de conviver com as diferentes emoções que o jogo ocasiona. Enfim, o jogo envolve um contexto complexo, que contribui de maneira significativa para o desenvolvimento integral da criança.

Diante dessas reflexões, verificamos que a vivência esportiva não se limita ao aspecto físico da prática, aos movimentos que o aluno realiza durante a aula. Ela tem sentido quando encarada como uma prática que envolve o aluno na sua pluralidade, nos seus aspectos históricos, culturais, físicos e sociais. Uma vez inserida nessa multiplicidade e complexidade, a vivência esportiva torna-se uma prática educacional, e é esse o pressuposto que deve nortear as aulas de iniciação esportiva. Corroboramos com a idéia apresentada por Santana (2005) de que a iniciação esportiva é um fenômeno complexo, composto por diversas unidades que se inter-relacionam de forma dinâmica e imprevisível. É um fenômeno carregado de sensibilidade, com implicações que interferem no processo de desenvolvimento humano da criança. Segundo o autor, é de fundamental importância que a iniciação esportiva seja compreendida dentro dessa complexidade, e não apenas como uma etapa, uma fase de treinamento que visa à formação de um atleta profissional. 
Outro aspecto importante relacionado à proposta teórica do TGFU é o de que os jogos reduzidos praticados durante a aula devem estar acompanhados de uma reflexão coletiva sobre a prática e a elaboração de estratégias para os próximos jogos. Verifica-se, portanto, que a verbalização é um aspecto importante no ensino a partir da proposta pedagógica do TGFU, já que é a partir da conversa e análise sobre os jogos que o conhecimento se constrói. É no processo de diálogo e reflexão sobre o jogo que os alunos analisam seu desempenho e elaboram estratégias para os próximos jogos. É no processo de ação-reflexão-diálogo-ação que se dá a construção de conhecimentos, percepções e habilidades sobre o jogo.

A partir dessas reflexões, é possível perceber que o professor deve estar atento para intervir durante os jogos reduzidos propostos em aula. Entretanto, essa intervenção não deve ter como objetivo a correção dos gestos técnicos dos alunos, mas sim promover perguntas, questionamentos que levem o aluno a uma reflexão sobre sua prática durante o jogo. A reflexão e as questões que o professor coloca são aspectos importantes dentro da abordagem do TGFU. As perguntas devem levar o aluno a analisar criticamente sua atuação durante o jogo, promovendo uma compreensão e um conhecimento mais abrangente acerca da lógica do jogo.

Segundo a proposta pedagógica do TGFU, as habilidades do aluno são construídas a partir do contexto do jogo. É dessa forma que a aprendizagem faz sentido, e não quando o aluno aprende mecanicamente a execução de um gesto técnico, a partir da sua repetição, de forma isolada do contexto do jogo. Um movimento não tem um fim em si mesmo, mas deve sempre estar associado à percepção do jogo, à capacidade de criação do aluno, à capacidade de tomar decisões.

A percepção do jogo é de fundamental importância dentro da perspectiva do TGFU, ela é encarada como um processo ativo de interpretação das informações do ambiente. Está associada ao conhecimento, vivências e valores construídos ao longo da vida de cada sujeito. É a forma como o sujeito interpreta o mundo, está relacionada com a sua formação social e histórica, e interfere em todos os seus processos cognitivos.

Assim, fica clara a deficiência de aulas de iniciação esportiva que se pautam em modelos tecnicistas, nas quais o aluno está submetido à repetição e à mecanização de movimentos. É necessário que os professores compreendam a complexidade que o jogo oferece, suas múltiplas possibilidades de reflexões que abrangem não só o momento do jogo, mas que podem se estender para toda a vida do aluno. É a partir desses pressupostos que a vivência esportiva pode ser abordada como uma prática educacional com possibilidades que contribuem com a formação integral do aluno.

Light e Fawns (2003) salientam ainda que pensamento e ação estão em constante relação de interdependência, ou seja, não existe uma relação de causalidade entre eles, a ação não é fruto do pensamento, ambos estão correlacionados. Nesse sentido, as ações realizadas durante o jogo não são consideradas como produtos da atividade cognitiva, mas sim como eventos que manifestam a interação entre aspectos cognitivos, afetivos, físicos e sociais do sujeito. $\mathrm{O}$ conhecimento do jogo surge a partir de sua prática, do exercício de lidar com as diversas e complexas situações que o jogo promove, e discutir e refletir sobre essa prática.

Portanto, a proposta pedagógica que se baseia no TGFU se dá no encontro entre pensamento, linguagem e ação. $\mathrm{O}$ professor deve propor atividades que promovam 
um processo de aprendizagem ativa, em que o aluno é levado a refletir sobre sua prática, refletir sobre o jogo. Pode-se verificar que o papel atribuído ao aluno nesse modelo de ensino não se limita a um reproduzir mecânico das atividades. Ele assume uma postura crítica em relação à aula e a sua atuação nela, é considerado na sua materialidade, na sua relação com os outros alunos e com a sociedade.

Dessa forma, a proposta pedagógica TGFU não se pauta no ensino de determinada habilidade, mas sim em uma forma de pensar o jogo como um contexto de tomada de decisão e reflexão. O foco está na atividade do jogo e no processo de aprendizagem ativa do aluno, as suas ações são encaradas na complexidade que envolve seus elementos sociais, afetivos e emocionais. As técnicas surgem a partir do jogo, no exercício de realizar a habilidade de forma eficiente, no contexto adequado durante o jogo.

A partir da análise dos elementos que envolvem a prática de ensino pautada no modelo do TGFU, Kirk, Brooker e Braiuka (2000) levantam alguns pressupostos teóricos que devem nortear a prática pedagógica dos professores que se baseiam nesse modelo de ensino. O primeiro aspecto apontado pelos autores é que o aprendizado é um processo ativo, no qual o aluno se apropria de elementos presentes no meio ambiente (por exemplo, os jogos realizados durante a aula), interpreta essas informações e, a partir desse processo, produz conhecimento.

Além desse aspecto, Kirk, Brooker e Braiuka (2000) ressaltam que a interação social durante a aula é importante no processo de aprendizagem. As interações que se estabelecem entre os alunos, ou entre o professor-aluno, assumem um papel central na qualidade do ensino. Nesse sentido, fica claro que a abordagem do TGFU reconhece a complexidade do contexto de jogo. Dessa forma, é importante que o professor reconheça essa característica no momento de avaliar suas aulas, não basta que se avalie o desempenho de um aluno na aula. É necessário verificar como se estabeleceram as relações entre os sujeitos durante a aula, e como essas relações contribuíram para a construção do conhecimento.

Esse é um aspecto importante do TGFU, nesse modelo o professor não deve apresentar propostas, reflexões ou avaliações prontas e esperar que os alunos apenas a aceitem passivamente. A relação entre professor-aluno deve ser norteada por questionamentos constantes. Por exemplo, quando o professor verifica que determinada atividade que ele havia proposto não está se desenvolvendo da maneira esperada, ele não deve simplesmente modificar a atividade. Cabe a ele questionar os alunos, fazendo com que eles percebam os motivos que levaram a atividade a não dar certo e quais alterações poderiam ser feitas para garantir o sucesso na atividade.

Nesse sentido, o papel do aluno não é o de apenas executar as propostas apresentadas pelo professor, mas sim o de participar criticamente na elaboração das atividades, avaliando o seu próprio desempenho, o de seus colegas e, inclusive, o do professor. Dessa maneira, estabelecem-se ricas e complexas redes de relações no contexto da aula, e não uma relação unidirecional em que o professor propõe e o aluno executa.

Outro aspecto interessante apontado por Kirk, Brooker e Braiuka (2000) é que o aluno não chega à aula como uma "página em branco". É comum que a criança tenha algum tipo de contato com o esporte fora do contexto da aula, seja pela televisão, ou pela própria prática em outros espaços. Para os autores, é fundamental que o professor 
reconheça esse aspecto durante as aulas, considere a vivência que a criança teve com o esporte. Segundo Kirk, Brooker e Braiuka (2000), isso interfere na maneira pela qual ela interpreta o jogo e as diferentes relações que estabelece com ele.

As novas atividades que o professor pretende propor durante a aula serão interpretadas pela criança a partir dessas vivências anteriores que ela teve com o esporte. Nesse sentido, cada aluno estabelece um significado para a prática esportiva, cada aluno terá sua percepção e compreensão do jogo. Desse modo, o conhecimento na aula se constrói a partir do encontro entre o que o professor propõe e os significados que o aluno já carregava.

Diante disso, é importante que as aulas de iniciação esportiva aproximem-se da cultura infantil. Essa idéia é defendida por Paes (2001), para quem os jogos utilizados durante as aulas podem ser facilitadores para o resgate da cultura infantil. Ou seja, a partir de adaptações de jogos e brincadeiras que as crianças já conhecem é possível direcionar as atividades tendo em vista o aprendizado coletivo.

A fim de contribuir com a aplicação da proposta pedagógica do TGFU na prática, Kirk, Brooker e Braiuka (2000) elaboraram um modelo teórico dividido em dois momentos para auxiliar o professor na elaboração da estrutura de suas aulas. A primeira fase desse modelo corresponde à compreensão elementar do jogo. Nesse momento, os alunos devem analisar o jogo na tentativa de perceber as táticas, estratégias, as regras, as técnicas e habilidades tanto físicas quanto psicológicas e comunicativas necessárias durante o jogo. A partir dessa compreensão, o aluno é capaz de perceber nos jogos reduzidos a semelhança com a situação de jogo formal. Isso auxilia na compreensão sobre a lógica dos elementos do jogo. Cabe ao professor, durante as aulas, formular questões que levem o aluno a verbalizar respostas que contribuam com esse processo de compreensão. É neste processo de jogo, reflexão e verbalização que se dá a construção da aprendizagem.

É importante que exista uma progressão gradual na dificuldade dos jogos reduzidos, e que esses se aproximem cada vez mais à estrutura do jogo formal. Os jogos reduzidos podem ser planejados a partir de diferentes referenciais, podem se aproximar do jogo formal em relação à tática ou estratégia, ou em relação às técnicas e habilidades.

A segunda fase sugerida por Kirk, Brooker e Braiuka (2000) é a da compreensão do jogo a partir das relações entre seus elementos. Nesse momento, o aluno deve ser levado a estabelecer relações entre os diferentes elementos (táticos, estratégicos e técnicos) de diferentes jogos. Ele deve perceber que jogos reduzidos que envolvem situações de passe e recepção estão associados a elementos como o de noção espacial e temporal, comunicação, que também estão presentes em diversos esportes coletivos. É papel do professor promover reflexões entre seus alunos a fim de que eles percebam quais os elementos dos jogos reduzidos podem auxiliam na compreensão do jogo formal.

\section{Considerações finais}

A Pedagogia do Esporte corresponde a um amplo campo de pesquisa e atuação profissional. Neste texto, buscamos apresentar e discutir propostas pedagógicas que tenham como preocupação central a criança, e tenham como norte teórico o potencial educativo que o esporte possui. 
Nesse sentido, apresentamos a teoria do Teaching Games For Understanding, que aponta para a multiplicidade de fatores e elementos envolvidos no processo de iniciação esportiva. Segundo essa proposta teórica, as aulas de iniciação esportiva devem estruturar-se em jogos reduzidos, e é a partir do contato com os diferentes elementos que compõem o contexto desses jogos que o aluno constrói o conhecimento. É importante ressaltar que os Jogos Reduzidos envolvem um contexto complexo que possibilita uma variada vivência motora, exige a aplicação de diferentes técnicas e a estruturação de táticas para solucionar as dificuldades que o jogo ocasiona. Essas situações-problema exigem da criança inteligência e criatividade para serem solucionadas. Além disso, o ambiente do jogo representa uma possibilidade de discussão de valores e princípios, elementos que podem contribuir na formação da criança e acompanhá-la para o resto da vida. Acreditamos que a vivência destes jogos contribui de maneira significativa para a formação integral da criança.

No entanto, conforme discutido, o jogo por si só não contribui no processo educacional do aluno. É preciso que o professor realize intervenções constantes durante a aula, de forma a possibilitar uma reflexão dos alunos. Durante essa reflexão, os alunos devem falar sobre sua atuação durante o jogo, a integração com os companheiros da equipe, a relação com os adversários, a forma com que eles solucionaram as situações-problema que o jogo ocasionou. Enfim, deve haver uma reflexão sobre a prática, uma vez que é nesse processo de ação-reflexão-diálogo-ação que se constrói o conhecimento.

É de fundamental importância que a vivência esportiva seja analisada dentro dessa complexidade. Nesse sentido, a vivência esportiva deve ser abordada como um momento em que o aluno está inserido em um contexto complexo, em uma rede de elementos que possibilitam uma multiplicidade de ação e reflexão. Nessa rede estão envolvidos aspectos como a inteligência, criatividade, integração com os companheiros, percepção de si mesmo, percepção do outro, ou seja, aspectos que contribuem para a educação integral do aluno. Diante disso, é importante que o processo de iniciação esportiva esteja pautado nos três elementos interligados de ensino, vivência e aprendizagem. Cabe ao professor trabalhar a vivência esportiva a partir dessa perspectiva e, com isso, fazer com que as aulas de iniciação esportiva contribuam de maneira significativa para a educação integral do aluno.

The pedagogical approach of Teaching Games for Understanding: reflections on an initial physical education program

\begin{abstract}
The Teaching Games for Understanding (TGFU) approach suggests that initial sports education should be based on reduced games. For the authors Who follow this theoretical orientation, reduced games practice contributes to the understanding of the tactical logic of the formal game. This article aims at discussing TGFU's approach, which currently plays an important role in world publications on the teaching and learning of sports. We try to relate TGFU theories and authors to the reflections conducted by Brazilian scholars of sports pedagogy. From the dialogue between these two groups of authors, we believe it is possible to contribute to the construction of new viewpoints on the phenomenon of initial sports education.
\end{abstract}

Keywords: Sports Pedagogy - Initial Sports Education - Teaching Games For Understanding. 


\section{El método teaching games for understanding: reflexiones sobre la iniciación deportiva}

\section{Resumen}

El método de TGFU defiende que la iniciación esportiva si las bases en juegos reducidos. Para los autores que siguen esta línea teórica, la práctica de estos juegos contribuye para la comprensión de la lógica táctica del juego formal. Este artículo tiene como objetivo principal realizar discusiones sobre el método de TGFU. Este método ocupa un papel importante en publicaciones mundiales sobre enseñanza y aprendizaje esportiva. Creemos para ser de la importancia básica para insertar esta teoría en la escena nacional. Con esto, buscamos relacionar las reflexiones de los autores del TGFU con las reflexiones de estudioso del Pedagogía del deporte en el Brasil. Del diálogo entre estos dos árboles teóricos, sea posible contribuir para la construcción de nuevas perspectivas en el fenómeno de la iniciación del esportiva.

Palabras-clave: Deporte - Pedagogía - Iniciación Deportiva - Teaching Games For Understanding

\section{Referências}

BALBINO, H. F. ,PAES, R. R; Processo de ensino-aprendizagem do basquetebol: perspectivas pedagógicas. In: DE ROSE JUNIOR, D.; TRICOLI, V. Basquetebol uma visão integrada. Barueri: Manole, 2005.

BUNKER; THORPE. The curriculum model. Rethinking Games Teaching. Loughborough University Of Technology, p.7-10, 05 out. 1986. Disponível em: <http:// www.educ.uvic.ca/Faculty/thopper/index.htm>. Acesso em: 25 maio 2008.

KIRK, D.; BROOKER, R. BRAIUKA, S. Teaching games for understanding: a situated perspective on student learning. In: Annual Meeting of the American Educational Research Association. 2000. Disponível em: <http://eric.ed.gov/ERICDocs/ data/ericdocs2sq1/content_storage_01/0000019b/80/16/48/28.pdf> Acesso em: 26 de maio de 2008.

LIGHT, R. Accessing the inner world of children: The use of student drawings in research on children's experiences of Game Sense Proceedings In: The Asia Pacific Conference on Teaching Sport and Physical Education for Understanding. 2007. p. 72-83. Disponível em: <http://www.proflearn.edsw.usyd.edu.au/resources/papers/Proceedings_TGfU_06_AsiaPacificSport.pdf>.

LIGHT, R., FAWNS, R. The embodied mind: blending speech and action in games teaching through TGfU. Quest, v. 55, p. 161-176, 2003. Disponível em $<$ http:// www.educ.uvic.ca/Faculty/thopper/index.htm>. Acesso em: 25 de maio de 2008.

MITCHELL, S.; OSLIN, J.; GRIFFIN, L. Sport fundations for elementary Physical

Education: a tactical games approach. Kent, Ohio: Human Kinetics, 2003.

PAES, R. R. Educaşão fisicica escolar: o esporte como conteúdo pedagógico do ensino fundamental. Canoas: Ed. da Ulbra, 2001.

SADI, R. S.; COSTA, J. C.; SACCO, B. T. Ensino de esportes por meio de jogos:desenvolvimento e aplicações. Revista Pensar a Prática, vol. 11.1, p. 17-26, jan./jul. 2008. Disponível em: <http://www.revistas.ufg.br/index.php/fef/article/ view/1298/3615>. Acesso em: 10 de maio de 2009. 
SANTANA, W. C. de. Pedagogia do esporte na infância e complexidade. In: PAES, R. R.; BALBINO, H. F. (Orgs.). Pedagogia do esporte: contextos e perspectivas. Rio de Janeiro: Guanabara Koogan, 2005. p. 1-22

Recebido em: 09 de março de 2009

Revisado em: 12 de maio de 2009

Aprovado em: 18 de maio de 2009

\section{Endereço para correspondência}

Sabine Zink Bolonhini

Faculdade de Educação Física - UNICAMP

Avenida Érico Veríssimo, 701 - Cidade Universitária Zeferino Vaz - Barão Geraldo

13.083-851 - Campinas - São Paulo - Brasil - Caixa Postal 6134 